\title{
The Dynamics of Brain Concentrations of Phenylalanine and Its Clinical Significance in Patients with Phenylketonuria Determined by in Vivo ${ }^{1} \mathrm{H}$ Magnetic Resonance Spectroscopy
}

\author{
J. PIETZ, R. KREIS, C. BOESCH, J. PENZIEN, D. RATING, AND N. HERSCHKOWITZ \\ Department of Pediatric Neurology, University of Heidelberg, Federal Republic of Germany [J.Pietz, \\ D.R.], and Departments of Magnetic Resonance Spectroscopy and Methodology [R.K., C.B.] and \\ Pediatrics [J.Penzien, N.H.], University of Berne, Switzerland
} \begin{abstract}
ABS
Cerebral concentrations of phenylalanine (PHE) were mea-
sured by means of quantitative in vivo ${ }^{1} \mathrm{H}$ MR spectroscopy in 8 adult patients treated early for phenylketonuria type I. A 1.5 Tesla routine magnetic resonance scanner, localization sequence with short echo time $(20 \mathrm{~ms})$, and a fully automated data processing scheme were used. Baseline plasma PHE concentrations were $1.04(0.70-1.39) \mathrm{mmol} / \mathrm{L}$ PHE with concurrent brain PHE concentrations of $0.27(0.13-0.41) \mathrm{mmol} / \mathrm{kg}$ of wet weight resulting in a plasma/brain ratio of 4.12 . Plasma and brain concentrations correlated significantly (Kendall $\tau_{\mathrm{b}}=0.91, p<$ 0.01 ). During an oral load with a single dose of $100 \mathrm{mg} \mathrm{L}$-PHE per $\mathrm{kg}$ of body weight in four patients, plasma levels steeply increased. Concurrent brain PHE increase was less steep, was significantly delayed, and still continued up to $20 \mathrm{~h}$ postload. Despite the proven rise in plasma and brain concentrations of PHE, neuropsychologic examinations revealed no impairment of attentional and fine motor abilities from preload up to $20 \mathrm{~h}$ postload. (Pediatr Res 38: 657-663, 1995)
\end{abstract}

PHE, phenylalanine

CSF, cerebrospinal fluid

IQ, intelligence quotient

IDC, index of dietary control

MR, magnetic resonance

MRI, magnetic resonance imaging

${ }^{1} \mathbf{H}$ MRS, proton magnetic resonance spectroscopy

NMR, nuclear magnetic resonance

PKU, phenylketonuria

ROI, region of interest

sqrt, square root

T, Tesla

VEP, visual evoked potential

WAIS-R, Wechsler adult intelligence scale (revised version)

TE, echo time

TR, relaxation time
Some 40 y after its first description (1), the PHErestricted diet for patients with PKU is still an outstanding example of the successful treatment of inborn errors of metabolism. Despite the overall favorable outcome compared with untreated patients, open questions remain and new problems arise. 1) The influence of the strictness of the diet on outcome has been demonstrated clearly (2), but it is still unclear why some patients with normal outcome seem to be "protected," in spite of adhering to no diet at all (3), whereas other patients on diet show a decline in e.g. IQ. 2) A reversible impairment of cognitive function and EEG

Received February 27, 1995; accepted May 11, 1995.

Correspondence: Joachim Pietz, Department of Pediatric Neurology, University of Heidelberg, Im Neuenheimer Feld 150, D-69120 Heidelberg, FRG.

Supported by German Research Foundation (Grant DFG (Pi196/3-1)

Data partly presented at the Annual Meeting of the European Society Society for Paediatric Research, Paediatric Week Holland, June 29th to July 6th, Rotterdam, The Netherlands. activity has been demonstrated during PHE challenges (4). The decrease in performance was, however, only weakly related to the total increase of plasma PHE, demonstrating an interindividually variable sensitivity to PHE. 3) Neurologic symptoms have been observed in adult patients off diet (5), which were partly reversible after reinstitution of a PHE-restricted diet. In these, but also in neurologically unaffected PKU patients, white matter changes have been observed in MRI (6). Lowering plasma PHE levels improved changes in some cases.

In all areas mentioned, PHE and its impact on brain morphology and function seems to be a key explanatory factor. Access to a compartment "closer to the brain" is possible by lumbar puncture, although in otherwise healthy patients it is ethically questionable. Using an animal model of hyperphenylalaninemia, Avison et al. (7) were able to show that PHE was detectable by ${ }^{1} \mathrm{H}$ MRS in the brains of rabbits in vivo. Post- 
mortem measurement of brain PHE levels correlated closely to the in vivo concentration estimated from ${ }^{1} \mathrm{H}$ MR spectra.

Modern methodologic approaches in MRS make it possible to go beyond concentration estimations via peak ratios $(8-10)$ and to quantitate metabolites in molar concentrations. ${ }^{1} \mathrm{H}$ MR spectroscopy thus offers a new approach for measuring brain PHE concentrations directly and noninvasivly. The aim of our study was therefore 1 ) to investigate in vivo the plasma/brain correlation of PHE concentrations in PKU patients by means of localized ${ }^{1} \mathrm{H}$ MRS, 2) to examine the dynamics of PHE influx into brain tissue during an oral load with L-PHE, and 3) to correlate brain PHE concentrations to brain function during the load.

\section{METHODS}

Eight (1 woman, 7 men) patients with PKU type I (PHE > $1200 \mathrm{mmol} / \mathrm{L}$ on a normal diet) were included. Mean age was 23 (21-26) y. Diet onset was $<2.5$ mo. Plasma PHE was determined by gas column chromatography twice monthly up to $12 \mathrm{y}$ of age and monthly thereafter. According to the procedure of other outcome studies $(2,4)$, for subsequent 6-mo periods the median of all PHE values was calculated. An IDC $_{\text {plasma }}$ was calculated as the mean of all 6-mo-medians up to $12 \mathrm{y}$ of age. Clinical evaluation included IQ (German version WAIS-R), routine EEG (10/20 system), checkerboard VEP, and a standardized neurologic investigation. None of the patients had any history of other factors disturbing brain development. Data of 13 (5 women, 8 men) healthy volunteers with a mean age of $27(19-47)$ y served as basis for the calculation of averaged normal spectra.

PHE plasma levels during this study were determined enzymatically (Quantase ${ }^{\mathrm{R}}$, PHE assay, Porton Cambridge, UK). In four male patients an oral PHE load was performed. A single dose of $100 \mathrm{mg}$ of purified L-PHE/kg of body weight was given along with a small meal rich in carbohydrates. After the load patients were monitored for 2 wk until plasma PHE levels were back in their usual range.

Before and $20 \mathrm{~h}$ after the PHE load, patients underwent a neuropsychologic examination. A sustained attention test (Dot Pattern Exercise) from a computerized neuropsychologic test battery (11) was used to evaluate the effects of the PHE load on concentration ability. Mean series time (ST) of this test gives information about the speed of information processing, whereas the SD (SD ST) measures the stability of performance. Patients then performed four tests of fine motor abilities (12). 1) "Steadiness" measures static tremor. The contacts of a stylus to the rim of a small hole are registered (N errors). 2) The "Maze" task measures dynamic tremor and eye-hand coordination. Subjects run a stylus through a metal maze (N errors and time errors). 3) "Sticks" is a pegboard test. Performance time is recorded (time). Poor coordination and low speed impair performance. 4) "Pursuit rotor" is a task to determine visual-motor performance. Lost contacts between a moving rotor and a contact pencil are registered (time error).

To estimate white matter changes and to guide MRS localization, PKU patients were examined by standard cranial MRI including spin-echo T1-weighted (TR $660 \mathrm{~ms}$, TE $20 \mathrm{~ms}$ ), proton density and T2-weighted (TR 2400, TE 20, $80 \mathrm{~ms}$ ) images. White matter changes were rated as discrete (restricted to parieto-occipital periventricular white matter), moderate (extending to subcortical regions) or severe (involving frontal and temporal lobes as well).

Localized proton MR spectra were acquired on a 1.5-T GE Signa routine MR scanner in two settings. In setting A (patient nos. 1-8) a standard quadrature head coil was used. Spectra were acquired from a large voxel placed in the midline right above the ventricular system involving supraventricular white and gray matter of both hemispheres (typically $60 \times 70 \times 20$ $\mathrm{mm}$ ). In setting B (patient nos. 1 and $4-8$ ) a surface receive coil (diameter $13 \mathrm{~cm}$ ) was used. Spectra were acquired mainly from periventricular white matter in parietal and occipital lobes (typically $30 \times 30 \times 25 \mathrm{~mm}$ ). Usual acquisition parameters were: PRESS sequence (Bottomley PA 1984 U.S. patent 4480 228) with outer volume suppression, water presaturation, and phase rotation (13), $\mathrm{TE}=20 \mathrm{~ms}$, repetition period $\mathrm{TR}=$ 3 s, 128-512 averages, 2048 data points. For the determination of different brain compartments and water referencing, a series of separate recordings with different echo times, but no water suppression was acquired (9).

The fully automatic data processing scheme used to quantitate the PHE signal is described in detail elsewhere (15). Only the basic steps shall be alluded to here. Due to underlying baseline peaks in the downfield portion of the normal cerebral MR spectrum, the singlet-like peak of the phenyl protons of PHE at $7.37 \mathrm{ppm}$ was determined in difference spectracalculating patient spectra minus baseline spectrum averaged from healthy controls. Absolute PHE tissue levels were determined using the intensity of the brain tissue water signal, obtained from a three compartment model with brain tissue water, CSF, and structural material as constituents (9). Although the displayed spectra were scaled by tissue water only, PHE concentrations were obtained taking into account PHE signal contributions from CSF and blood.

CSF concentrations were calculated from plasma concentration according to a plasma to CSF ratio of 4.15 , which was derived from the literature, calculating a weighted mean from the CSF data of $75 \mathrm{PKU}$ patients (15). Whether PHE from blood is NMR visible or not, is a priori unclear. Motion as well as different relaxation characteristics may render it unobservable. The loading experiments in this study gave insight into this question. When calculating brain PHE concentrations in the experiments with high nonequilibrium plasma PHE levels, a correction for PHE signal contributions from blood $(\sim 5 \%$ relative cerebral blood volume) yielded the bizzarre result that in all of the four patients brain PHE levels would initially have dropped after the intake of L-PHE. There is no plausible physiologic explanation for this, and it is more likely that PHE from blood is not or only partially NMR-visible. All results in this study were therefore derived, assuming PHE from blood to be undetectable. Because PHE concentrations in patients are derived from difference spectra (patient minus control), the normal cerebral PHE concentration in healthy sujects, reported to be as low as $0.05 \mathrm{mmol} / \mathrm{L}(21,22)$, was added to the calculated PHE concentrations in patients. 
Brain tissue concentrations are given in units of $\mathrm{mmol} / \mathrm{kg}$ wet weight, plasma concentrations are listed in units of $\mathrm{mmol} / \mathrm{L}$. Concentration gradients of PHE between plasma and brain are reported as dimensionless values, obtained by a units conversion using brain and plasma density values of $1.05 \mathrm{~kg} / \mathrm{l}$. Due to the small number of observations, correlational analysis was restricted to the calculation of rank correlation coefficients (Kendall's $\tau_{\mathrm{b}}$ ), performed by $\mathrm{SAS}^{\mathrm{R}}$ version 6.03. Probability values $\mathrm{p}$ are obtained assuming that Kendalls sum s/sqrt (var(s)) is normally distributed. The study was approved by the ethical commitee of the University of Heidelberg. All subjects included gave informed consent.

\section{RESULTS}

\section{Measurements under steady state conditions}

Clinical data. Baseline plasma PHE levels of all patients were in their usual range before the start of the study. Four patients (nos. 3, 4, 6, and 7) were still on a PHE-restricted diet, four patients (nos. 1, 2, 5, and 8) were off diet. The neurologic investigation revealed no abnormal signs except discrete intention tremor in patient no. 6. Although all patients were treated before 2.5 months after birth, IQs in adult age ranged widely. For the 8 patients IDC $_{\text {plasma }}$ correlates significantly with IQ in adult age $\left(\tau_{\mathrm{b}}=-0.79, p<.05\right)$. In all eight patients $\mathrm{T} 2$ weighted images revealed patchy, nonspace-occupying white matter changes most prominent in the parieto-occipital lobes. Further clinical data are listed in Table 1.

${ }^{1} \boldsymbol{H} \boldsymbol{M R}$ spectroscopy. The upfield portion of MR spectra revealed no apparent abnormalities with respect to the concentrations of the standard metabolites $N$-acetylaspartate, (total) creatine, choline, myo-inositol and glutamine plus glutamate when comparing patients and controls (Fig. 1). In all difference spectra from patients (minus control), a peak of primarily unknown origin was identified in the downfield portion of the spectrum at $7.37 \mathrm{ppm}$ with both settings. The solution spectrum of PHE features a strong peak at the same chemical shift (Fig. $1)$. The excess peak in the patient's spectra can therefore be attributed to the phenyl protons of PHE, whereas the $\alpha$ and $\beta$ protons of PHE cannot be identified due to their small amplitudes. All spectra were transformed automatically to absolute tissue concentrations of PHE according to the described data processing scheme (Table 2). Plasma PHE and brain PHE concentrations acquired with setting A correlated significantly
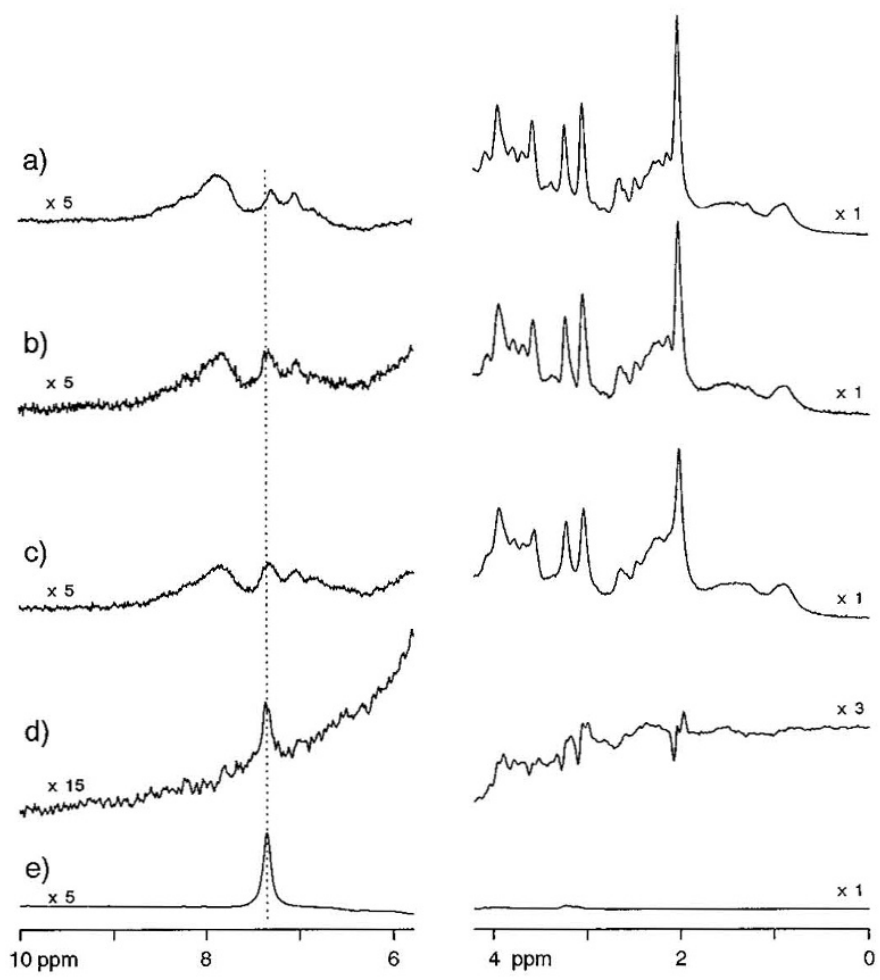

Figure 1. Representative ${ }^{1} \mathrm{H}$ MR spectra; the downfield part with the peak of the phenyl protons of PHE at $7.37 \mathrm{ppm}$ on the left, the normal appearing upfield region on the right. The central region from 4.2 to $5.8 \mathrm{ppm}$ with residual resonances from water is left out. (a) Averaged baseline spectrum of 10 healthy, age-matched controls, recorded with setting B (surface coil). The downfield portion of the spectrum is mostly unassigned. (b) Cerebral spectrum of patient no. 1, recorded with setting B (concurrent plasma PHE 1.14 $\mathrm{mmol} / \mathrm{L})$. (c) Cerebral spectrum of the same subject, recorded with setting A (head coil, larger voxel size). (d) Difference spectrum of $b$ minus $a$ (line width adapted plus $1 \mathrm{~Hz}$ of additional exponential line broadening, scaled by factor 3). (e) Spectrum from a model solution of PHE, line broadened to match the spectrum in $d$.

$\left(\tau_{\mathrm{b}}=0.91, p<0.01\right.$ ) (Fig. 2). The mean ratio of plasma PHE to brain PHE was 4.12 (3.23-4.95). Plasma/brain PHE ratios were in the same range for very different plasma PHE concentrations between 0.70 and $1.4 \mathrm{mmol} / \mathrm{L}$ and independent of plasma PHE values under steady state conditions.

Spectra acquired with the surface receive coil (setting B) lead to somewhat higher concentrations (Table 2) with a mean plasma/brain ratio of 3.55 . For the six patients investigated with both settings, brain PHE concentrations derived from

Table 1. Clinical data of eight adult PKU patients including age, sex, concurrent baseline plasma PHE, IDC plasma, IQ in adult age, visual EEG evaluation, VEP and standard MRI evaluation

\begin{tabular}{|c|c|c|c|c|c|c|c|c|}
\hline $\begin{array}{c}\text { Patient } \\
\text { no. }\end{array}$ & $\begin{array}{l}\text { Age } \\
\text { (yrs) }\end{array}$ & Sex & $\begin{array}{c}\text { PHE } \\
(\mathrm{mmol} / \mathrm{L})\end{array}$ & $\begin{array}{l}\mathrm{IDC}_{\text {plasma }} \\
(\mathrm{mmol} / \mathrm{L})\end{array}$ & $\begin{array}{c}\text { IQ } \\
\text { (WAIS-R) }\end{array}$ & $\mathrm{EEG}^{*}$ & VEP & MRI $†$ \\
\hline 1 & 22 & M & 1.14 & 0.69 & 61 & gsl/gep & Normal & ++ \\
\hline 2 & 22 & $\mathrm{M}$ & 1.16 & 0.61 & 95 & Normal & path. & $++/ b$ \\
\hline 3 & 26 & $\mathrm{M}$ & 0.70 & 0.34 & 101 & Normal & Normal & + \\
\hline 4 & 24 & $M$ & 0.94 & 0.21 & 112 & Normal & Normal & + \\
\hline 5 & 23 & M & 1.39 & 0.40 & 93 & Normal & path. & $+++/ b$ \\
\hline 6 & 22 & $\mathrm{M}$ & 0.80 & 0.30 & 110 & Normal & Normal & $++/ b$ \\
\hline 7 & 21 & $\mathrm{~F}$ & 0.79 & 0.31 & 106 & Normal & Normal & + \\
\hline 8 & 24 & M & 1.36 & 0.29 & 102 & Normal & Normal & $++/ \mathrm{c}$ \\
\hline
\end{tabular}

*EEG: gsl = general slowing of background activity, gep $=$ generalized epileptiform activity.

† MRI: + discrete, ++ moderate,+++ severe white matter changes, $c=$ involvement of cerebellum, $b=$ involvement of brainstem. 
Table 2. Baseline plasma PHE of eight adult PKU patients and concurrent brain PHE concentrations, determined by localized in vivo ${ }^{I} H$ MRS in two different settings

\begin{tabular}{|c|c|c|c|}
\hline Patient & $\begin{array}{l}\text { Plasma PHE } \\
(\mathrm{mmol} / \mathrm{L})\end{array}$ & $\begin{array}{c}\text { Brain PHE } \\
\text { (mmol/kg } \\
\text { wet } \\
\text { weight) }\end{array}$ & $\begin{array}{c}\text { Ratio* } \\
\text { (plasma/brain) }\end{array}$ \\
\hline \multicolumn{4}{|c|}{ Standard head coil } \\
\hline 1 & 1.14 & 0.26 & 4.17 \\
\hline 2 & 1.16 & 0.34 & 3.25 \\
\hline 3 & 0.70 & 0.13 & 4.95 \\
\hline 4 & 0.94 & 0.25 & 3.52 \\
\hline 5 & 1.39 & 0.41 & 3.23 \\
\hline 6 & 0.80 & 0.17 & 4.60 \\
\hline 7 & 0.79 & 0.17 & 4.41 \\
\hline 8 & 1.36 & 0.28 & 4.86 \\
\hline Mean & 1.04 & 0.27 & 4.12 \\
\hline \multicolumn{4}{|c|}{ Surface receive coil } \\
\hline 1 & 1.14 & 0.35 & 3.15 \\
\hline 4 & 0.94 & 0.29 & 3.14 \\
\hline 5 & 1.39 & 0.44 & 2.99 \\
\hline 6 & 0.80 & 0.26 & 2.89 \\
\hline 7 & 0.79 & 0.17 & 4.40 \\
\hline 8 & 1.36 & 0.28 & 4.70 \\
\hline Mean & 1.07 & 0.30 & 3.55 \\
\hline
\end{tabular}

* For the calculation of ratios brain tissue concentrations were transformed to $\mathrm{mmol} / \mathrm{L}$ according to a brain tissue density of 1.05 .

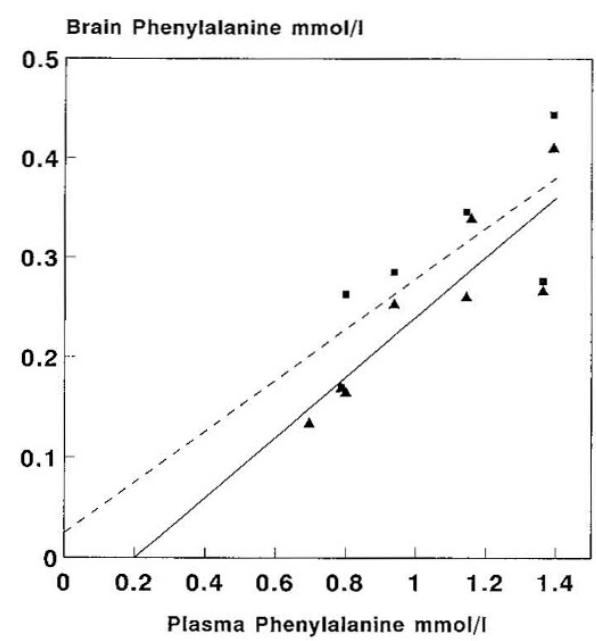

Figure 2. Plasma concentrations and concurrent brain concentrations of PHE, determined by in vivo 'H MR spectroscopy from eight adult PKU patients with two data acquisition settings. In setting A (triangles) a head coil and a large voxel size in a supraventricular position was used; spectra in setting B (squares) were recorded with surface receive coil from a smaller voxel localized primarily in parieto-occipital white matter. The correlation between plasma and brain concentration is demonstrated by linear regression solutions for data from setting A (solid line) and B (dotted line).

setting B were about $17 \%$ higher compared with the results with setting A. Correlations between plasma PHE and brain PHE concentrations acquired with setting B were significant as well $\left(\tau_{\mathrm{b}}=0.73, p<0.05\right)$. Brain PHE concentrations derived from both settings correlated with each other $\left(\tau_{\mathrm{b}}=0.69, p<\right.$ $0.05)$. Differences between brain PHE concentrations acquired with settings A and B were not dependent on the size of plasma PHE.

The individual $\mathrm{IDC}_{\text {plasma }}$, a marker for the total impact of PHE on the brain, was divided by the individual plasma/brain

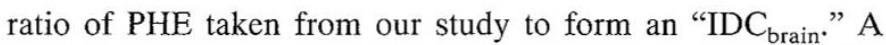
reanalysis for the ratios derived from setting $\mathrm{A}$ revealed that the correlation "IDC $\mathrm{Ibain}_{\mathrm{b}} \times \mathrm{IQ}$ " was reduced to $\tau_{\mathrm{b}}=-0.64,(p$ $<0.05)$. For setting $\mathrm{B}, \mathrm{IDC}_{\mathrm{brain}} \times \mathrm{IQ}$ was reduced to $\tau_{\mathrm{b}}=$ -0.47 (NS). Thus, an influence of the individual plasma/brain ratio of PHE, taken from our MRS study in adult life, on the correlation of "IDC plasma $\times$ IQ" cannot be confirmed.

\section{Dynamic measurements using an oral load of L-PHE}

Clinical data. The oral load with $100 \mathrm{mg} \mathrm{L-PHE} / \mathrm{kg}$ of body weight in patient nos. 1-4 led to a steep increase of plasma PHE (Fig. 3a). Only in patient no. 1 was plasma PHE determined in short intervals immediately after the start of the load. In this patient a maximum of plasma PHE was reached $1.75 \mathrm{~h}$ postload. The mean increase of plasma PHE was $0.72 \mathrm{mmol} / \mathrm{L}$ from $0.99(0.70-1.16) \mathrm{mmol} / \mathrm{L}$ PHE preload to 1.71 (1.42$1.90) \mathrm{mmol} / \mathrm{L}$ PHE $5 \mathrm{~h}$ postload. At $20 \mathrm{~h}$ postload plasma PHE levels (1.59 (1.44-1.65) $\mathrm{mmol} / \mathrm{L} \mathrm{PHE})$ had already started to decrease in three patients.

${ }^{1} \boldsymbol{H} \boldsymbol{M R S}$. The increase of plasma PHE led to an increase of the PHE peak area at 7.37, whereas the other parts of the spectra remained unchanged. In setting $A$ the increase was confirmed from start to $5 \mathrm{~h}$ postload as well as from 5 to $20 \mathrm{~h}$ postload (Figs. 3b and 4). The increase of brain PHE concentrations from preload to $5 \mathrm{~h}$ postload was less steep (26\%) compared with the increase in plasma PHE (64\%). Brain PHE measured by ${ }^{1} \mathrm{H}$ MRS continued to increase significantly from $5 \mathrm{~h}$ postload up to $20 \mathrm{~h}$ postload, whereas plasma PHE had already decreased. The total increase of brain PHE from preload to $20 \mathrm{~h}$ postload was $54 \%$ (from 0.24 to $0.37 \mathrm{mmol} / \mathrm{kg}$ PHE). According to the different kinetic characteristics of brain PHE influx and plasma PHE increase, plasma/brain ratios increased during the load from baseline preload measurement (3.97) to $5 \mathrm{~h}$ postload (5.24) and then decreased again $20 \mathrm{~h}$ postload (3.91).

Brain PHE determinations using setting B during the loading experiment (patient nos. 1 and 4) led to comparable results with a $24 \%$ increase of brain PHE from preload to $5 \mathrm{~h}$ postload in comparison to a $72 \%$ plasma PHE increase. The total increase of brain PHE from preload to $20 \mathrm{~h}$ postload was $31 \%$ (from 0.32 to $0.58 \mathrm{mmol} / \mathrm{kg}$ PHE). The course of plasma/brain ratios during the load was comparable to setting $\mathrm{A}$.

Neuropsychologic examinations. The neuropsychologic examination and motor tasks performed during the load did not reveal any significant change in any relevant variable of these tests. The data of the sustained attention task and the tasks for fine motor abilities remained stable from preload baseline examination to the examination $20 \mathrm{~h}$ postload (Table 3 ). Also, patients did not complain of any discomfort or impairmant of vigilance along with the PHE challenge.

\section{DISCUSSION}

We were able to demonstrate, that it is possible to detect and quantitate brain PHE concentrations by ${ }^{1} \mathrm{H}$ MRS using a clinical routine MR scanner at plasma levels, which are usual in patients with PKU. The most noteworthy and promising aspect of the current report, however, is that localized ${ }^{1} \mathrm{H}$ MRS 

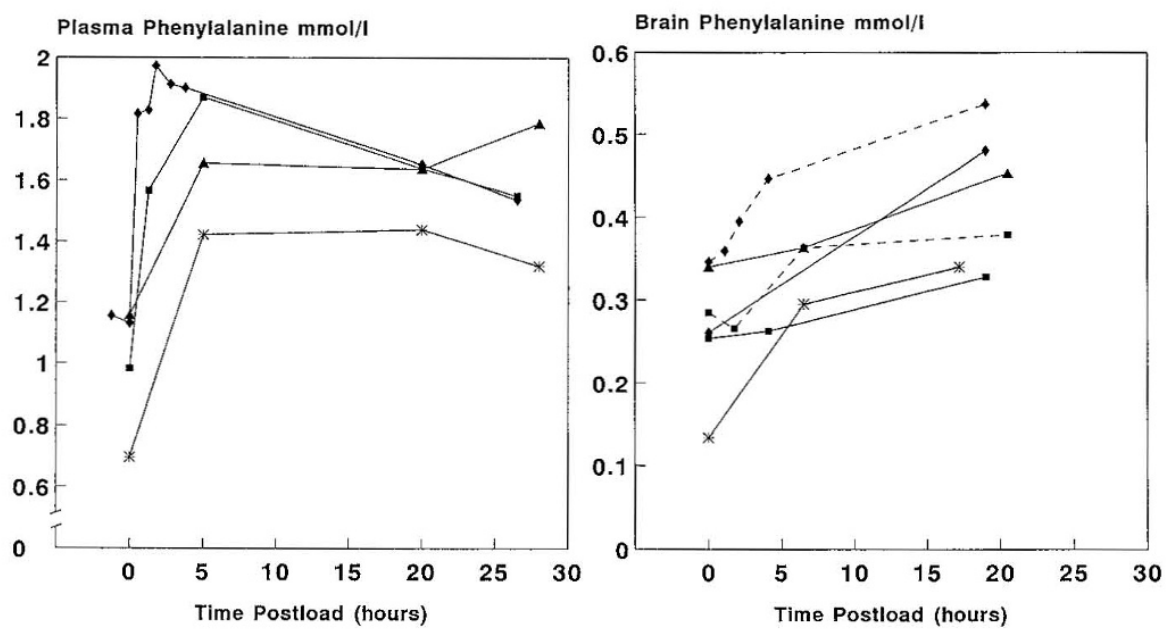

a)

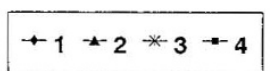

b)

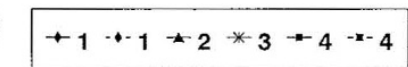

Figure 3. (a) Demonstration of the steep increase of plasma PHE levels in four adult PKU patients after an oral load with $100 \mathrm{mg} / \mathrm{kg}$ of body weight purified L-PHE from baseline values preload to $20 \mathrm{~h}$ postload. (b) The much slower influx of PHE into brain tissue, reflected in the delayed increase of brain PHE concentrations, determined by in vivo ${ }^{1} \mathrm{H}$ MRS. All four patients (nos. 1-4) were examined with setting A (solid line), patient nos. 1 and 4 were also examined with setting B (dotted line).

a)

$20 \mathrm{~h}$

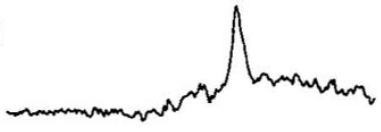

$5 \mathrm{~h}$

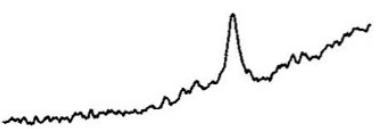

$\mathrm{oh}$

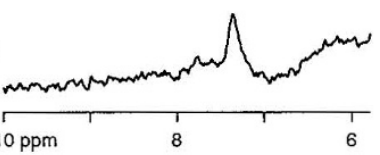

b)

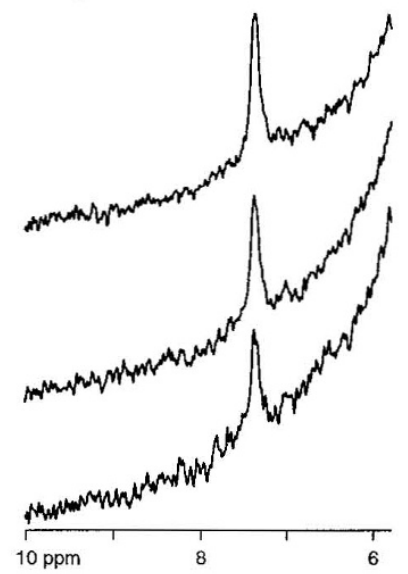

Figure 4. Difference ${ }^{1} \mathrm{H}$ MR spectra (patient minus averaged normal spectrum), acquired in vivo with setting $\mathrm{A}$ (head coil, large voxel) from PKU patient no. $3(a)$ and with setting B (surface receive coil) from patient no. $1(b)$ before as well as 5 and $20 \mathrm{~h}$ after an oral load with $100 \mathrm{mg} / \mathrm{kg}$ of body weight purified L-PHE. The increase of the difference peak at $7.37 \mathrm{ppm}$ due to the phenyl-ring protons of PHE is demonstrated clearly.

also allows the investigation of the temporal course of PHE entry into the brain after an oral PHE load.

Because concentrations of PHE in PKU patients are below the detection limit for standard ${ }^{1} \mathrm{H}$ MRS examinations, it was necessary to adapt special acquisition parameters discussed in detail in Kreis et al. (15). They comprised a PRESS localization sequence with short echo time and two alternative settings in terms of receive coil and ROI size. Setting A (large supraventricular ROI, standard head coil) is preferable with respect to signal to noise ratio. Setting B (smaller ROI, surface coil) is advantageous with respect to size and reproducibility of line widths. In our study, slightly different concentrations were derived from the two settings (see Table 2). Regional concentration gradients, different compartmentation, as well as error

of measurement, may have contributed to these differences. Comparisons of the upfield portion of the patient's as well as the downfield portion of the baseline spectra indicates that this apparent regional variation may be genuine and not an artifact of differing acquisition parameters.

The averaged spectrum of healthy controls features a peak of unknown origin with a maximum at $7.30 \mathrm{ppm}$ near the point of interest at $7.37 \mathrm{ppm}$ where PHE is detected. Because brain PHE concentrations in healthy controls are reported to be as low as $0.05 \mathrm{mmol} / \mathrm{kg}$ of wet weight $(16,17)$, this baseline peak cannot be due to free PHE. Calculating PHE peak areas without correcting for this peak will overestimate PHE concentrations. A major point of our approach to quantitate PHE in vivo was therefore to use difference spectroscopy (18) with identical acquisition and data processing for patients and matched healthy controls.

A second important issue is the utilization of an objective, fully automatic, and operator-unbiased data processing and quantitation scheme, taking cerebral compartmentation into account also. Both ROIs studied were separated into two compartments. The first compartment represents brain tissue composed of intra- plus extracellular space with the volume of extracellular space between 15 and 20\% (19). The second compartment is due to CSF which, in controls, accounts for about $5 \%$ of the voxel volume in setting $\mathrm{A}$ ( $2.5 \%$ in setting $\mathrm{B})$. In PKU patients this space is about double in both settings, which means that there is an additional CSF-like space in patients. An enlargement of CSF space by cortical atrophy is one explanation, particularly for setting A which includes sulci and interhemispheric space. The voxel in setting B includes MRI-visible white matter changes. It seems therefore most likely that additional water within white matter of PKU patients contributes to this CSF-like space as well to the hyperintensities in T2-weighted images observed in all eight patients. As the true concentration of PHE in CSF is not known and cannot be measured reliably by MRS, our correction for 
Table 3. Test results of four adult PKU patients for a sustained attention task (dot pattern exercise, DPE) and four subtests (steadiness, maze, sticks, pursuit rotor) from a test battery for fine motor abilities (MLS) as well as concurrent plasma and brain concentrations of PHE before and $20 \mathrm{~h}$ after an oral load with $100 \mathrm{mg}$ L-PHE/kg body weight

\begin{tabular}{|c|c|c|c|c|c|c|}
\hline \multirow[b]{2}{*}{ Test } & \multicolumn{3}{|c|}{ Preload } & \multicolumn{3}{|c|}{ Postload } \\
\hline & Min & $\operatorname{Max}$ & Mean & Min & $\operatorname{Max}$ & Mean \\
\hline \multicolumn{7}{|l|}{ PHE } \\
\hline Plasma $(\mathrm{mmol} / \mathrm{L})$ & 0.70 & 1.16 & 0.98 & 1.44 & 1.65 & 1.59 \\
\hline $\begin{array}{l}\text { Brain (mmol/kg wet weight) } \\
\text { determined by }{ }^{1} \mathrm{H} \text { MRS setting } \mathrm{A}^{*}\end{array}$ & 0.13 & 0.34 & 0.25 & 0.33 & 0.48 & 0.40 \\
\hline \multicolumn{7}{|l|}{ DPE } \\
\hline Series time (s) & 6.1 & 8.3 & 7.4 & 6.5 & 8.3 & 7.3 \\
\hline SD series time (s) & 0.8 & 2.7 & 1.7 & 1.1 & 2.5 & 1.9 \\
\hline $\mathrm{N}$ error & 26 & 60 & 38 & 35 & 70 & 48 \\
\hline \multicolumn{7}{|l|}{ MLS } \\
\hline Steadiness: $\mathrm{N}$ error & 0 & 3 & 0.8 & 0 & 5 & 1.5 \\
\hline \multicolumn{7}{|l|}{ Maze: } \\
\hline $\mathrm{N}$ error & 10 & 22 & 16 & 11 & 20 & 16 \\
\hline Time error (s) & 5 & 8 & 7 & 6 & 18 & 10 \\
\hline Sticks: Time (s) & 386 & 467 & 418 & 353 & 443 & 386 \\
\hline Rotor: Time error (s) & 27 & 66 & 47 & 42 & 61 & 49 \\
\hline
\end{tabular}

* Standard head coil.

PHE from CSF in the voxels, based on the plasma PHE concentration, implies some uncertainty. Fairly consistent values for the ratio of plasma to CSF PHE are, however, reported in the literature as summarized by Kreis et al. (15). In addition, because brain concentrations determined by ${ }^{1} \mathrm{H}$ MRS and estimated CSF concentrations differ little, the correction for PHE from CSF leads to maximal changes on the order of only a few percent. However, due to the different water content in brain tissue and CSF, it is still imperative to distinguish between the two compartments when water is used as the internal standard for quantitation, and an appreciable CSF space is included in the ROI. Also, it has to be mentioned that in the oral loading experiments which lead to nonsteady state situations, the CSF correction may be more important, but also leads to somewhat larger uncertainties in quantitation.

Brain tissue concentrations of PHE determined in our study by ${ }^{1} \mathrm{H}$ MRS are lower than those reported by Avison et al. (7) for an animal model of PKU. They report a ratio of serum to brain concentrations determined by ${ }^{1} \mathrm{H}$ MRS in vivo of 2.65 , but differences in MR methodology, the referencing to creatine, as well as uncontrolled effects of the administration of $\alpha$-methylphenylalanine to the integrity of the blood brain barrier and brain metabolism have to be taken into account. The only data on PHE determinations by means of in vivo ${ }^{1} \mathrm{H}$ MRS in humans were presented by Novotny et al. (20). In their study PHE was detectable in five adult patients off diet at plasma concentrations above $1.4 \mathrm{mmol} / \mathrm{L}$ using a $2.1-\mathrm{T}$ magnet. PHE was calculated in relation to an assumed creatine concentration of $9.0 \mathrm{mmol} / \mathrm{L}$. Johannik et al. (21) did not detect a PHE peak in PKU patients which is well explained by their acquisition parameters.

Brain PHE levels determined by ${ }^{1} \mathrm{H}$ MRS in our study seems to be in some contrast to the data reported from autopsy of untreated PKU patients by McKean (22), which were in the range of 0.85 to $1.0 \mathrm{mmol} / \mathrm{kg}$ of wet weight. Data from plasma are not available, but usual plasma levels of untreated PKU patients are in the range of about 1.5 to $2.0 \mathrm{mmol} / \mathrm{L}$ PHE. For comparison with our study, it has to be taken into account that PHE values from autopsy material may overestimate in vivo concentrations because of autolysis, which was shown for non-PKU controls when comparing fresh biopsy ( 0.05 $\mathrm{mmol} / \mathrm{kg}$ of wet weight PHE) and autopsy material $(0.13$ $\mathrm{mmol} / \mathrm{kg}$ of wet weight PHE) $(16,23)$. Under these assumptions our results fit well with the biochemically determined PHE values from autopsied brains of untreated patients. It is noteworthy that regional differences for cerebral PHE concentrations were found in controls (23).

To our knowledge, the present study comprises the first report of dynamic data regarding the influx of PHE into human brain in vivo. It was shown that the influx of PHE through the blood-brain barrier continued during our whole observation period. In an animal study reported by McKean et al. (24), brain PHE showed a much steeper increase after loading rats with L-PHE intraperitoneally. The plasma/brain ratio increased from a baseline value of 1.1 to 4.35 at $30 \mathrm{~min}$ postload and then decreased again to 2.4 at $60 \mathrm{~min}$ postload. It is not clear to what extent blood in brain vessels contributed to these results, and there are no results for longer observation times. Experiments with much longer observation times in PKU patients could therefore further clarify the dynamics of PHE influx into brain tissue as well as the efflux after lowering blood levels of PHE.

With respect to the ratios derived from setting $\mathrm{A}$, the brain concentration of our eight patients would vary from 0.20 to $0.31 \mathrm{mmol} / \mathrm{kg}$ of wet weight PHE for a given plasma concentration of $\sim 1.0 \mathrm{mmol} / \mathrm{L}$ PHE, which are substantial differences. Our expectation that these interindividual differences in plas$\mathrm{ma} /$ brain ratios would play a clinically relevant role by enhancing or reducing the cerebral toxicity of a certain plasma PHE level could not be verified in the patients studied. The correlation between long-term PHE levels during the first $12 \mathrm{y}$ of age and IQ in adult life was reduced when taking the individual plasma/brain ratio into account. Due to the small number of patients on which this correlation is based, this result is only preliminary. Also, it is known that the functional properties of 
the blood brain barrier are not a stable attribute over time. The influx of PHE into brain tissue may change dramatically during development (17). This was proven in an animal model (25) as well as by the determination of PHE in cord blood and brain tissue of aborted human PKU fetuses (26), in which a plasma/ brain ratio of about 1 proves a higher influx of PHE into brain. As there is wide intraindividual variation in the course of time there may be also interindividual variation leading to relatively "high" plasma/brain ratios in adult life in patients with "low" plasma/brain ratios during childhood and vice versa. Thus, it may be incorrect to relate data from adult life to childhood, which is, regarding the brain damage by PHE, the more important period.

${ }^{1} \mathrm{H}$ MRS also promises to become a tool in the investigation of the effects of elevated PHE after terminating dietary treatment. Several studies have shown that the concurrent PHE level may have a "toxic" effect on cognitive functions. An impairment of brain function can also be detected by electroencepalographic methods, usually noted as a slowing of background activity in spectral analysis (4). We did not detect any deterioration in attentional and fine motor performance for our patients after a single loading dose of L-PHE, although plasma and brain concentrations were well above the baseline levels. A simple explanation for this result is lacking, but it seems possible that cognitive impairment may be tied to prolonged periods (4) of elevated PHE. Little is known, however, about transport of amino acids in extracellular space, the uptake and utilization by glial and neuronal cells, trans- and intracellular transport after an abrupt change of concentrations, as during our PHE load (27). It should also be noted that the changes of brain metabolism due to elevated PHE levels and its effects on neuronal function are still largely unknown (28).

Summarizing our first results in the use of ${ }^{1} \mathrm{H}$ MRS, we find that PHE can be quantitated in vivo by localized ${ }^{1} \mathrm{H}$ MRS in concentrations which are common in adult PKU patients. Although plasma as well as brain tissue concentrations of PHE increased substantially in a loading experiment, we did not detect any impairment of attentional and fine motor abilities. It was shown that the different kinetics of PHE in plasma and brain tissue can be traced by ${ }^{1} \mathrm{H}$ MRS and may give new insights into the relation between brain PHE concentrations and impairments of brain function.

Acknowledgement. The authors thank Hildgund Schmidt, M.D., Department of Pediatrics, University of Heidelberg, for supplying clinical data of PKU patients to the study.

\section{REFERENCES}

1. Bickel H, Gerrard J, Hickmans EM 1954 The influence of phenylalanine intake on the chemistry and behaviour of a phenylketonuric child. Acta Paediatr Scand 43:64-77
2. Azen CG, Koch R, Friedman EG, Berlow St, Coldwell J, Krause W, Matalon R, McCabe E, O'Flynn M, Peterson R, Rouse B, Scott CR, Sigman B, Valle D, Warner R 1991 Intellectual development in 12-year-old children treated for phenylketonuria. Am J Dis Child 145:35-39

3. Primrose DA 1983 Phenylketonuria with normal intelligence. J Ment Def Dis 27:239-246

4. Pietz J, Schmidt E, Matthis P, Kobialka B, Kutscha A, de Sonneville L 1993 EEGs in phenylketonuria. I. Follow-up to adulthood; II. Short-term diet-related changes in EEGs and cognitive function. Dev Med Child Neurol 35:54-64

5. Thompson AJ, Smith I, Brenton DP, Youl BD, Rylance G, Davidson DC, Kendall B, Lees AJ 1990 Neurological deterioration in young adults with phenylketonuria. Lancet 336:602-605

6. Thompson AJ, Tillotson S, Smith I, Kendall B, Moore SG, Brenton DP 1993 Brain MRI changes in phenylketonuria. Associations with dietary status. Brain 116:811821

7. Avison MJ, Herschkowitz N, Novotny EJ, Petroff OAC, Rothman DL, Colombo JP, Bachmann C, Shulman RG, Prichard JW 1990 Proton NMR observation of phenylalanine and an aromatic metabolite in the rabbit brain in vivo. Pediatr Res 27:566-570

8. Hennig J, Pfister H, Ernst T, Ott D 1992 Direct absolute quantification of metabolites in the human brain with in vivo proton spectroscopy. NMR Biomed 5:193-199

9. Ernst T, Kreis R, Ross B 1993 Absolute quantitation of water and metabolites in the human brain. I. Compartments and water. J Magn Reson B 102:1-8

10. Kreis R, Ernst T, Ross B 1993 Absolute quantitation of water and metabolites in the human brain. I. Metabolites. J Magn Reson B 102:9-19

11. Sonneville de L, Njiokiktjien C 1988 Aspects of information processing. Suyi Publications, Amsterdam, pp 120-123

12. Schoppe K-J 1974 Das MLS-Gerät: Ein neuer Testapparat zur Messung feinmotorischer Leistungen. Diagnostika 20:43-46

13. Hennig J 1992 The application of phase rotation for localized in vivo spectroscopy with short echo times. J Magn Reson 96:40-49

15. Kreis R, Pietz J, Penzien J, Herschkowitz N, Boesch C 1995 Identification and quantitation of phenylalanine in the brain of patients with phenylketonuria by means of localized in vivo ${ }^{1} \mathrm{H}$ magnetic resonance spectroscopy. J Magn Reson Ser B 107:242-251

16. Perry TL, Hansen S, Berry K, Mok C, Lesk D 1971 Free amino acids and related compounds in biopsies of human brain. J Neurochem 18:521-528

17. Lajtha AL, Maker HS, Clarke DD 1981 Metabolism and transport of carbohydrates and amino acids. In: Siegel GJ, Albers RW, Agranoff BW, Katzman (eds) Basic Neurochemistry, 3rd Ed. Little, Brown, Boston, pp 329--352

18. Kreis R, Farrow N, Ross BD 1991 Localized ${ }^{1} \mathrm{H}$ NMR spectroscopy in patients with chronic hepatic encephalopathy. Analysis of changes in cerebral glutamine, choline and inositols. NMR Biomed 5:59-64

19. Oldendorf W 1987 The blood-brain barrier. In: Adelman G (ed) Encyclopedia of Neuroscience, Vol 1. Birkhäuser, Boston, pp 139-141

20. Novotny EJ, Avison MJ, Rothman DL, Seashore MR, Petroff OAC, Herschkowitz JW, Prichard JW, Shulman RG 1989 Detection of phenylalanine in the human brain. In: Proceedings of the SMRM, 8th Annual Meeting, Amsterdam, p 441

21. Johannik K, Van Hecke P, Francois B, Marchal G, Smet M-H, Jaeken J, Breysem L, Wilms G, Baert AL 1994 Localized brain proton NMR spectroscopy in young adult phenylketonuria patients. Magn Reson Med 31:53-57

22. McKean CM 1972 The effects of high phenylalanine concentrations on serotonin and catecholamine metabolism in the human brain. Brain Res 47:469-476

23. Perry TL, Berry K, Diamond S, Mok C 1971 Regional distribution of amino acids in human brain obtained at autopsy. J Neurochem 18:513--519

24. McKean CM, Boggs DE, Peterson NA 1968 The influence of high phenylalanine and tyrosine on the concentrations of essential amino acids in brain. J Neurochem 15:235-241

25. Antonas KN, Coulson WF 1976 Concentrations of phenylalanine and tyrosine in plasma and brain of rats treated with phenylalanine loads. Biochem Soc Trans 4:94-97

26. Fowler B, Horner J, Wraith JA, Sardhawalla IB 1988 Maternal PKU: Fetal blood and tissue amino acid concentrations in mid trimester. In: Proceedings of the 26th Symposium of the Society for the Study of Inborn Errors of Metabolism, Glasgow, Abstract 155

27. Betz AL, Goldstein GW, Katzman R 1994 Blood-brain-cerebrospinal fluid barriers. In: Siegel GJ, Agranoff BW, Albers RW, Molinoff PB (eds) Basic Neurochemistry. Molecular, Celluiar and Medical Aspects, 5th Ed. Raven Press, New York, pp 681-697

28. Scriver CR, Kaufman S, Eisensmith RC, Woo SLC 1995 The hyperphenylalaninaemias. In: Scriver CR, Beaudet AL, Sly WS, Valle D (eds) The Metabolic and Molecular Bases of Inherited Disease, Vol. I. McGraw-Hill, New York, pp 10151075 